\title{
Modern Language Range Mapping for the Study of Language Diversity
}

\author{
Hannah J. Haynie ${ }^{1,2}$ \\ Michael C. Gavin² \\ ${ }^{1}$ University of Colorado \\ ${ }^{2}$ Colorado State University
}

Corresponding Author:

Hannah J. Haynie

email: hannah.haynie@colorado.edu

tel: +1-303-735-8219

August 29, 2019

\begin{abstract}
Research regarding the ecology and evolution of languages has advanced rapidly in recent years, increasing demand for digital spatial location data for individual languages. However, language mapping and geographic information system (GIS) data creation has not kept pace with this demand. To date, language range information is typically contained in small, private regional datasets, paper maps and published illustrations, or in a very small number of global digital datasets. Each of these sources has advantages and disadvantages, and though these considerations may not be apparent to all data users, they can have significant impacts on research results. Mapping of language ranges is a particularly complex problem in regions where colonial histories have had dramatic effects on language diversity, language locations, and the relative representation of colonial and indigenous perspectives. Here we consider how the creation of digital language range data can better meet the needs of researchers interested in language diversity, discuss how better standards for data quality and transparency can be implemented for digital language range maps, and present a map of North American language ranges that has resulted from the use of these procedures and standards.
\end{abstract}




\section{Introduction}

Language maps have been published for centuries in paper books and atlases (e.g. Franquelin 1684; Wenker et al. 1926; Goddard 1996; Asher \& Moseley 2007). Recently, demand has grown for digital map products representing the locations and ranges of languages. For continent-scale or global-scale research, many scholars are dependent either on point representations indexed by databases like Glottolog, or the polygon representations of languages in licensed products like the World Language Mapping System (Hammarström, Forkel \& Haspelmath 2019; Global Mapping International (Firm) 2012). Although there has been interest among linguists in better utilizing digital tools to improve the state of language mapping for over a decade, linguist-driven attempts at improving the coverage and accessibility of language location GIS data have centered on map database projects that take advantage of the flexibility of GIS, but ultimately leave unsolved many important problems that complicate digital mapping of languages (LINGUIST List \& Indiana University 2019; Dahl \& Veselinova 2006). Access to high quality language maps and responsible use of spatial language data is still hindered by numerous obstacles.

Because language mapping is a multifaceted and understudied topic (Luebbering 2013), we focus specifically on the use of maps in the study of language diversity and the current problems posed by the use of language maps in this area of research. We propose that for this field, the problems of accessibility, quality, and transparency in language mapping are best addressed by the development of new standards which can be used to create well documented digital datasets that can be updated and cited.

While mapping the locations of ethnolinguistic groups is not a new practice, accessibility varies for the many language maps that have been created over time. Representations of language ranges are often found in the pages of other publications (e.g. Goddard 2005), limiting their accessibility to researchers who may not have the manpower, tools, or skills to digitize them. Digitized versions of some of these maps can be accessed online through individual researcher websites and collaborative web platforms (e.g. Wikimedia Commons 2019), however many of the regional datasets that are widely available in digital format have been separated from the citation information, temporal data, digitization history, and other details that might allow a researcher to assess whether the data is suitable for their research.

For global studies, digitizing entire atlases is prohibitively time consuming, driving scholars toward a small number of digital datasets (e.g. Global Mapping International (Firm) 2012; University of Groningen \& CIA World Factbook 2015). These convenient digital datasets are not appropriate for all uses. World Language Mapping System (WLMS) documentation, for example, describes the data in its primary language area layer as, "polygons delineating the linguistic homelands of most of the language-incountry entries in the Ethnologue." However, this source represents the spatial extent of many languages in terms of their contemporary ranges, not what most linguists consider to be their "homelands". Inferences from this spatial data about historical processes that may have affected these languages and their configuration in space may therefore reflect language loss, resettlement of ethnolinguistic groups, and other recent sociohistorical dynamics, rather than the longer-term language change and diversification processes of interest to certain researchers. This is particularly problematic in regions like North America, where the contemporary spatial distribution of indigenous languages may reflect European settlement and subsequent history more than the processes that shaped these languages' ranges prior to colonial contact. The magnitude of this problem is amplified by the fact that 
many users of this data may not be familiar enough with the homelands of various languages to identify error in this dataset with regards to consistent representation of language homelands.

Consistency and accuracy of language range representations can have consequences for many uses of language range data in studying language diversity from an ecological perspective. For example, the general global diversity patterns found in datasets with poor resolution or inaccurate boundaries may be qualitatively similar to the patterns of diversity that can be observed in detailed, accurate language range data, but using the less accurate ranges to extract climate or environmental data can introduce significant error. In other cases, missing information about the source or temporal focus of a language range map can make it difficult to assess the suitability of that spatial information for a particular research purpose.

Because language range maps have typically been produced by linguists, primarily for the purpose of illustrating individual grammars and comparative research publications, transparency has not been among the values embodied by the existing language map tradition. Maps are often drawn and published without any mention of sources referenced, acknowledgement of speaker communities whose knowledge informed those maps, or information about the context of map creation or principles and procedures followed in the process. Much of this information is not recoverable for published maps. However, the use of metadata and detailed source citation is important for tracing the information and influences that shape future map products. It can be hoped that enhancing the transparency surrounding sources will also help map users to understand the contexts and perspectives reflected in map data, including the extent to which missionary and colonial viewpoints have shaped the scholarly understanding of historical language geography.

\section{Methods}

We implement a set of standards for metadata, as well as a set of procedures for map digitization and polygon drawing, to create a maximally suitable map of North American languages for planned studies of language diversity patterns.

Because this dataset was created for the primary purpose of researching spatial patterns of language diversity, several of the representational decisions that were made in the process of its creation reflect priorities associated with specific intended uses. Languages are represented as occupying nonoverlapping ranges. Polygons are an abstraction that, for language ranges, conflates various types of settlement and land use, and cannot capture the complexities of language contact, bilingualism, and shared land use. We follow the majority tradition in North American language range mapping by treating language ranges as non-overlapping. However, we believe that work to investigate the nature of language boundaries and develop a more nuanced representation of the types of boundaries that exist could improve future versions of this dataset.

The research for which this dataset is intended focuses on processes of language diversification that occurred deeper in history than the European colonization of North America. Therefore, we have chosen to represent languages in the best approximation of their locations immediately prior to European colonial incursion. In practice, this means privileging information that represents the earliest documented locations of languages. However, the date represented by individual polygons varies across 
the extent of the dataset, and for some languages no particularly early documentation is available. We also encountered a significant body of language range data that provides little or no explicit information about time of reference. We considered this information only when it was clear that the approximate time of reference was at or immediately before European settlement. The result of this complex temporal reference problem is that the North American language range dataset created in this project considered data representing a range of dates from the late $16^{\text {th }}$ century to the early $20^{\text {th }}$ century, with a bulk in the $19^{\text {th }}$ century. We use the abstract "Time of European Contact" time reference as a shorthand for this spatial variability, and include references to source information for each polygon so that map users may recover more detailed information about temporal reference on a polygon-by-polygon basis.

Finally, results of research on language diversity can be influenced by missing data. In order to avoid artifacts of missing language range data in future research, to best of our ability, the mapping procedures followed in the creation of the North American language range map were designed to maximize spatial coverage. Although poorly attested languages may not be understood well enough to work out their relationships to other languages or to analyze their grammars, their existence matters to the spatial patterns of language diversity that we are interested in. Therefore, we opted to include languages mapped by prior scholars even when poor documentation has caused them to be excluded from the language database we use for reference (Hammarström, Forkel \& Haspelmath 2019).

\section{Metadata}

We include metadata in the vector map data file that describes the purpose, recommended and prohibited uses of the data, descriptions of assumptions and generalizations, time range of reference, user notes, date of map creation, and map creators. A credits field is also included, which contains more detailed citation information and acknowledgment of funding sources. An additional documentation file is distributed with the map dataset that provides a lengthier description of the data, information about features and attributes, and a list of sources for each polygon in the dataset. This metadata is intended to help users evaluate whether the dataset is appropriate for their intended uses, identify further information about the languages and language range representations included in the dataset, and avoid use of the data for purposes it is incompatible with (e.g. for legal claims or political purposes).

\section{Feature Attributes}

Each polygon in the dataset contains information for three attributes: Language Name, Glottolog ID, and Language Family.

Language Name contains the name of the language, as commonly used in scholarly literature. Though this may appear to be a straightforward piece of information, languages are often known by multiple names, or by multiple different spellings of a name. Selecting a single name for use in labeling a language map requires decision making regarding which names and orthographic conventions are widely recognized and, ideally, preferred by language speaker communities. At present, not all language names preferred by communities are in common usage in the scholarly community; we welcome feedback from communities on language name preferences and plan to make periodic updates to this data accordingly.

Glottolog ID is an identifier used to standardize language reference to entities cataloged in the Glottolog database. Not only are language names sometimes applied differently by different sources, but scholars 
do not always agree about what constitute separate languages, as opposed to dialects or entire branches of families. To avoid introducing our own biases into this dataset, we include a language-level Glottolog identifier for nearly all language polygons. This allows clear identification of the languages associated with each map polygon, as well as a means of directing users to information about language classification and bibliographic references. The inclusion of a standardized identifier also makes it possible to match data from other resources (e.g. Kirby et al. 2016) to the languages represented in this spatial dataset. There are several conditions under which languages may not match directly to a language-level entity in Glottolog. These are resolved as follows:

1. Poorly attested languages of unknown genealogical affiliation with no identifiable corresponding Glottolog entity are retained in the dataset, with "NA" for Glottolog ID.

2. Poorly attested languages from a known family with no exact match among language-level entities in the Glottolog database but an approximate match to a higher level grouping in Glottolog are matched to the Glottolog entry for that higher level grouping (e.g. the Laguna language in source maps would be matched to Glottolog's Eastern Keres).

3. Poorly attested languages from a known language family with a very closely related sister in Glottolog but no language-level entity in Glottolog that is an exact match are merged with the sister (e.g. Tecual is merged with Huichol).

4. Poorly attested languages from a known family with no corresponding language-level Glottolog entity and no sisters known to be especially closely related nor any immediately higher level groupings are retained, with "NA" in the Glottolog ID attribute and the appropriate family in the Language Family attribute (e.g. Nicola is kept in the map, with "NA" in the Glottolog ID field and "Athabaskan" in the Language Family field).

5. Entities included on all source maps as languages, with no finer detail available, and that correspond to a subgroup entity in Glottolog are retained and matched to the Glottolog ID of the corresponding subgroup entity.

6. Entities included on source maps as languages that correspond to a dialect entry in Glottolog are matched to the language-level parent entity in Glottolog (e.g. Mutsun and Rumsen are merged in a single polygon, with the Glottolog ID corresponding to Southern Ohlone).

The Language Family attribute includes the name of the highest level family entity to which the language can be positively identified as belonging to. This data is imported from Glottolog (Hammarström, Forkel \& Haspelmath 2019), purely for ease of use in situations where genealogical affiliation is a consideration. Minimally documented languages for which no relationships to other languages or families have been positively identified all have the value "Poorly Attested" for their language family; map users must be aware of this to avoid accidental treatment of these languages as related entities, and are cautioned about this in the dataset documentation.

\section{Boundary Drawing}

The boundaries drawn in the North American language range map are based on information contained in a large set of source maps. These maps were scanned in high resolution (minimum $300 \mathrm{dpi}$ ), georeferenced, rectified, and vectorized by project personnel, edited to include basic metadata, and collected as separate layers in a local file geodatabase. 
The continent-scale final dataset includes boundaries drawn by project personnel by considering the information in all digitized language range representations for any given language. In considering the information in alternative sources, a set of ranked priorities were used to evaluate sources:

1. Priority is given to maps that can be clearly determined to represent a time period at or immediately before the time of European contact for any language.

2. Priority is given to maps created by scholars known to have been in the field, interacting directly with language speaker communities.

3. Priority is given to maps with higher spatial resolution (i.e. more detailed maps).

4. Priority is given to maps that focus on a single language, subgroup, or family over region- or continent-scale maps.

5. Priority is given to maps that were created soon after the time period they document (i.e. an early map might be given preference over a map created many decades later to represent the same time period).

6. Priority is given to maps that were georectified with minimal error during the digitization process. Where error remains after georeferencing and rectification, both the location of boundaries and the locations of other nearby landmarks are considered in drawing boundaries.

While we find good overall agreement in the locations of languages, conflicting boundary placement across sources are not uncommon. We resolved language range boundary conflicts according to the following criteria:

1. Where a single, clearly preferred source can be identified based on priority criteria, that map is used as the primary source for a language's range in the aggregate map.

2. Where multiple sources are equally preferred, information from all preferred sources is considered in creating aggregate range boundaries for that language.

3. Where possible, aggregate boundaries drawn from multiple sources follow the generalized path of the boundary "bundle" that corresponds to all preferred sources.

4. Where boundaries do not align across preferred sources, natural landmarks are used to identify information that is consistent across sources, which is given priority in determining boundary locations relative to these landmarks.

5. Where no landmarks are identifiable in conflicting preferred sources, information from less preferred sources is also considered.

6. Where landmarks and lower priority sources are insufficient to resolve boundary conflicts, boundaries are drawn approximately midway between boundaries in all preferred sources.

The output of these procedures is a language range dataset that represents a best approximation of language locations for a maximal set of languages at approximately the time of European colonial contact. While this set of procedures is unable to erase the colonial legacy of prior language mapping projects or to perfectly correct the error in existing language range representations, it provides a single, well-documented continent-scale language range dataset with sufficient information for users to evaluate the appropriateness of the dataset as a whole for their intended uses, as well as to recover relevant details associated with each individual polygon. 
North American Language Range Map

This procedure was followed using a non-exhaustive set of source maps for the languages of North America. The resulting digital language range dataset (visualized in Fig. 1) includes spatial boundaries for 449 languages of North America representing their approximate distribution at the time of European contact.

Currently, the vector dataset associated with this map is available by contacting the corresponding author. The authors are currently in the process of making it available via a web portal for noncommercial purposes with appropriate attribution. Map revision will occur periodically based on feedback solicited from scholars and communities, and the availability of additional published sources. Revisions will be released in numbered versions to prevent confusion and enable stability of data and accurate citation by users. 


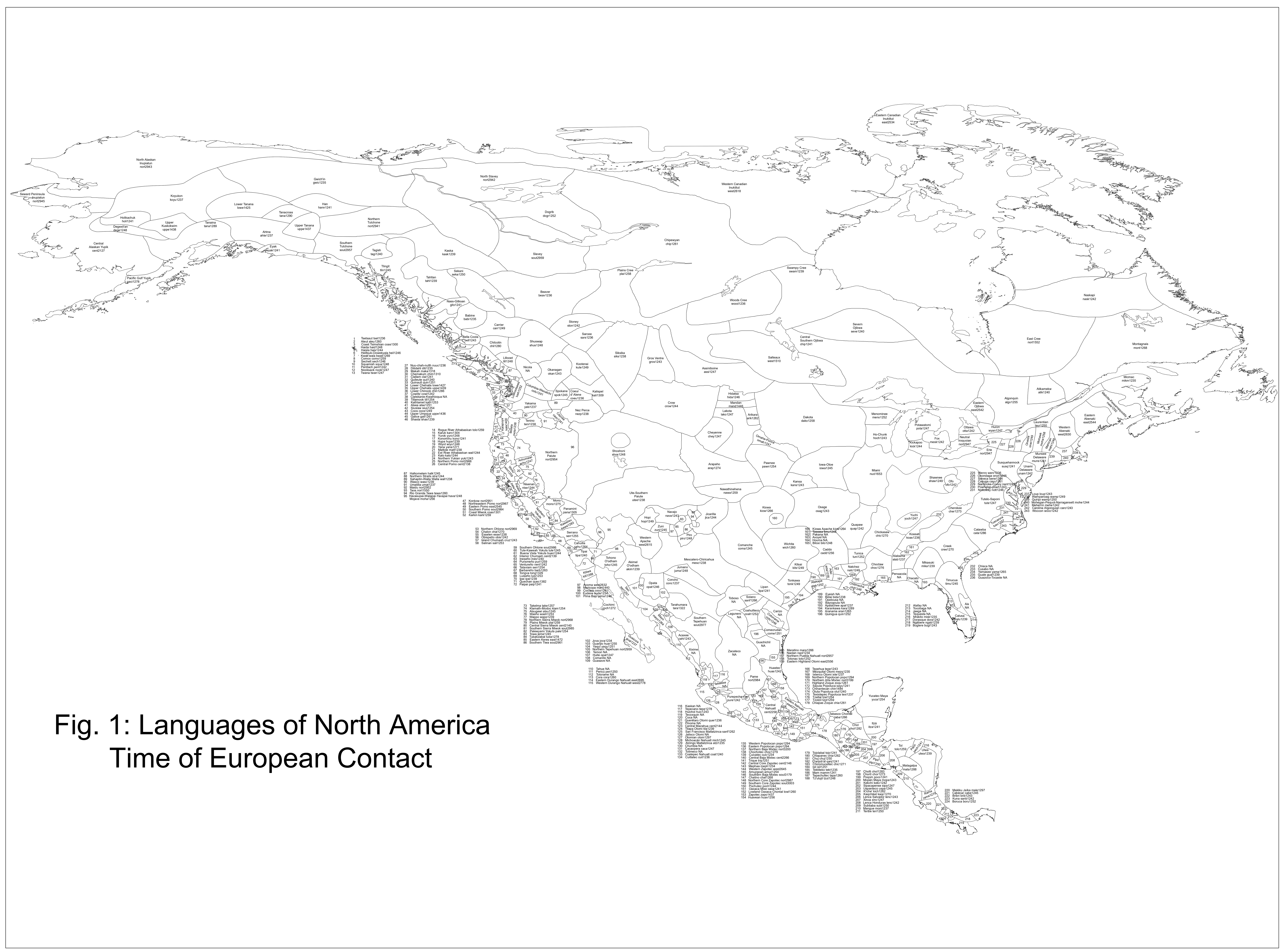




\section{Bibliography}

Anderton, Alice Jeanne. 1988. The language of the Kitanemuks of California. Los Angeles: University of California, Los Angeles Ph.D.

Asher, R. E. \& Christopher Moseley (eds.). 2007. Atlas of the World's Languages. New York: Routledge.

Barrett, Samuel Alfred. 1908a. The Ethno-geography of the Pomo and Neighboring Indians. University of California Publications in American Archaeology and Ethnology 8(1). 1-330.

Barrett, Samuel Alfred. 1908b. The geography and dialects of the Miwok Indians. University of California Publications in American Archaeology and Ethnology 6(2). 333-368.

Baumhoff, Martin A. 1958. California Athabascan Groups. University of California Anthropological Records 16(5). 157-237.

Bennyhoff, James Allan. 1961. The ethnogeography of the Plains Miwok. Davis, CA: Center for Archeological Research at Davis.

Binford, Lewis R. 1967. An Ethnohistory of the Nottoway, Meherrin and Weanock Indians of Southeastern Virginia. Ethnohistory 14. 103-218.

Callaghan, Catherine A. 1970. Bodega Miwok dictionary (University of California Publications in Linguistics 60). Berkeley: University of California Press.

Dahl, Östen \& Ljuba Veselinova. 2006. Language Map Server. ArcUser Online. https://www.esri.com/news/arcuser/0206/language_ms1of2.html.

Dayley, Jon P. 1989. Tümpisa (Panamint) Shoshone grammar. Berkeley: University of California Press.

Drucker, Philip. 1937. The Tolowa and their southwest Oregon kin. University of California Publications in American Archaeology and Ethnography 36. 221-300.

Franquelin, Jean Baptiste Louis. 1684. Carte de la Louisiane ou Des Voyages du Sr. De La Salle \& des pays qu'il a dècouverts depuis la Nouvelle France jusqu'au Golfe Mexique les annes 1679, 80, 81 \& 82. Paris.

Gatschet, Albert S. 1890. The Klamath Indians of southwestern Oregon. Washington, D.C.: Government Printing Office.

Geary, J.A. 1955. The language of the Carolina Algonkian tribes. In David Beers Quinn (ed.), The Roanoke voyages, 1584-1590: documents to illustrate the English voyages to North America under the patent granted to Walter Raleigh in 1854, 873-900. London: Hakluyt Society.

Gibson, Arrell M. 1971. The Chickasaws. Norman, OK: University of Oklahoma Press.

Global Mapping International (Firm). 2012. Global Mapping International World Language Mapping System, Version 16. GIS. Colorado Springs: Global Mapping International.

Goddard, Ives (ed.). 1996. Handbook of North American Indians, Vol 17: Languages. Washington, D.C.: Smithsonian Institution Press.

Goddard, Ives. 2005. The Indigenous Languages of the Southeast. Anthropological Linguistics 47(1). 160.

Goddard, Pliny Earle. 1923. Habitat of the Wailaki. University of California Publications in American Archaeology and Ethnography 20. 95-109.

Golla, Victor. 2011. California Indian Languages. Berkeley: University of California Press.

Granberry, Julian. 2011. The Calusa: Linguistic and Cultural Origins and Relationships. Tuscaloosa: University of Alabama Press.

Hammarström, Harald, Robert Forkel \& Martin Haspelmath (eds.). 2019. Glottolog 4.0. Jena: Max Planck Institute for the Science of Human History. https://glottolog.org/ (2 May, 2019).

Jackson, Jaon Baird. 2012. Yuchi Indian Histories Before the Removal Era. Lincoln, NE: University of Nebraska Press.

Jacobson, Daniel. 1960. The Origin of the Koasati Community of Louisiana. Ethnohistory 7(2). 97-120. 
Johnson, Jay K. 2000. The Chickasaws. In Bonnie G. McEwan (ed.), Indians of the Greater Southeast: Historical Archaeology and Ethnohistory, 85-121. Gainesville, FL: University Press of Florida.

Josserand, Judy Kathryn. 1983. Mixtec Dialect History (Proto-Mixtec and Modern Mixtec Text). New Orleans: Tulane University PhD Thesis.

Kirby, Kathryn R., Russell D. Gray, Simon J. Greenhill, Fiona M. Jordan, Stephanie Gomes-Ng, Hans-Jörg Bibiko, Damián E. Blasi, et al. 2016. D-PLACE: A Global Database of Cultural, Linguistic and Environmental Diversity. PLOS ONE 11(7). e0158391. doi:10.1371/journal.pone.0158391.

Kniffen, Fred B. 1928. Achumawi geography. University of California Publications in American Archaeology and Ethnology 23(5). 297-332.

Kniffen, Fred B., George F. Hiram \& George A. Stokes. 1987. The Historic Indian Tribes of Louisiana: From 1542 to the Present. Batton Rouge: Louisiana State University Press.

Krauss, Michael, Gary Holton, Jim Kerr \& and Colin T. West. 2011. Indigenous Peoples and Languages of Alaska. Fairbanks and Anchorage: Alaska Native Language Center. http://www.uaf.edu/anla/map.

Kroeber, Alfred L. 1932. The Patwin and their neighbors. University of California Publications in American Archaeology and Ethnology 29. 253-423.

Kroeber, Alfred L. 1963. Yokuts dialect survey. University of California Anthropological Records 11. 177251.

Kroeber, Alfred Louis. 1934. Uto-Aztecan Languages of Mexico. Berkeley: University of California Press. Kroeber, Alfred Louis. 1925. Handbook of the Indians of California. Washington D.C.: Smithsonian.

Langdon, Margaret. 1966. A Grammar of Diegueño: The Mesa Grande Dialect. Berkeley: University of California, Berkeley Ph.D.

León, Nicolás. 1903. Familias Lingüísticas de México. Ensayo de clasificación. Anales del Instituto Nacional de Antropología e Historia 1(7). 279-285.

Levy, Richard L. 1976. Costanoan Internal Relationships. Publications of the University of California Archaeological Research Facility 1-57.

LINGUIST List \& Indiana University. 2019. LLMap. http://www.llmap.org/about (2 September, 2019).

Lopez, Manuel Antonio \& Juliana Sis Iboy. 1998. Gramática del Idioma Achi. La Antigua Guatemala, Guatemala: Proyecto Lingüístico Francisco Marroquín.

Luebbering, Candice R. 2013. Displaying the geography of language: The cartography of language maps. Linguistics Journal 7(1). 39-67.

McEwan, Bonnie G. (ed.). 2000. Indians of the Greater Southeast: Historical Archaeology and Ethnohistory. Gainesville: University Press of Florida.

Milanich, Jerald T. 2000. The Timucua Indians of Northern Florida and Southern Gerogia. In Bonnie G. McEwan (ed.), Indians of the Greater Southeast: Historical Archaeology and Ethnohistory, 1-25. Gainesville: University Press of Florida.

Mithun, Marianne. 1999. The Languages of Native North America. Cambridge: Cambridge University Press.

Mithun, Marianne. 2017. The Iroquoian Language Family. In Alexandra Y. Aikhenvald \& Robert Malcolm Ward Dixon (eds.), Cambridge Handbook of Linguistic Typology, vol. III, 747-781. Cambridge: Cambridge University Press.

Newlin, Deborah L. 1982. The Tonkawa People: A Tribal History from Earliest Times to 1893. The Museum Journal 21. Lubbock, TX: West Texas Museum Association.

Nichols, Michael. 1974. Northern Paiute Historical Grammar. Berkeley: University of California, Berkeley Ph.D.

Nomland, Gladys Ayer. 1935. Sinkyone notes. University of California Publications in American Archaeology and Ethnography 36. 149-178. 
Powell, John Wesley. 1890. Map of linguistic stocks of American Indians. Image. Washington, D.C.: Bureau of Ethnology.

Quinn, Scott. 2004. Karuk Aboriginal Territory. Happy Camp, CA: Karuk Department of Tribal Lands Management.

Romero Castillo, Moises. 1975. Las Lenguas Mayas de Mexico. In Evangelina Arana de Swadesh (ed.), Las lenguas de México, Vol. 2. Cordoba, Mexico: Instituto Nacional de Anthropologia e Historia.

Sabo, G. 2000. The Quapaw Indians of Arkansas. In Bonnie G. McEwan (ed.), Indians of the Greater Southeast: Historical Archaeology and Ethnohistory, 178-203. Gainesville, FL: University Press of Florida.

Saunders, Rebecca. 2000. The Guale Indians of the Lower Atlantic Coast: Change and Continuity. In Bonnie G. McEwan (ed.), Indians of the Greater Southeast: Historical Archaeology and Ethnohistory. Gainesville: University Press of Florida.

Schroedl, G. 2000. Cherokee Ethnohistory and Archeology from 1540 to 1838. In Bonnie G. McEwan (ed.), Indians of the Greater Southeast: Historical Archaeology and Ethnohistory, 204-241. Gainesville: University Press of Florida.

Sjoberg, Andrée F. 1951. The Bidai Indians of Southeastern Texas. Southwestern Journal of Anthropology 7(4). 391-400.

Sturtevant, William C. \& Robert Fleming Heizer (eds.). 1978. Handbook of North American Indians, Vol. 8: California. Washington, D.C.: Smithsonian Institution Press.

Swanton, John R. 1922. Early History of the Creek Indians and their Neighbors. Washington D.C.: Government Printing Office.

Swanton, J.R. 1911. Indian Tribes of the Lower Mississippi Valley and Adjacent Coast of the Gulf of Mexico. Bureau of American Ethnology Bulletin 43.

University of Groningen \& CIA World Factbook. 2015. World_Languages (Feature Layer). https://geo.rug.nl/arcgis/rest/services/Culture_World/World_Languages/FeatureServer (2 September, 2019).

Waterman, T.T. 1920. Yurok geography. University of California Publications in American Archaeology and Ethnology 16. 177-314.

Wauchope, Robert \& Norman A. McQuown (eds.). 1967. Handbook of Middle American Indians. Vol. 5: Linguistics. Austin: University of Texas Press.

Wenker, Georg, Ferdinand Wrede, Bernhard Martin \& Walther Mitzka. 1926. Deutscher Sprachatlas. Marburg: N.G. Elwert.

Wikimedia Commons. 2019. Category: Linguistic maps. https://commons.wikimedia.org/wiki/Category:Linguistic_maps (2 September, 2019). 